\title{
Numeracy and Mathematics
}

\author{
JOHN O'DONOGHUE
}

\begin{abstract}
This brief report was prepared in response to a request by the Chairman, National Committee for Mathematics, Royal Irish Academy, to furnish further information concerning issues surrounding Numeracy and Mathematics for the committee's consideration at their meeting (1 March 2002). The report was also circulated to members of the National Sub-Commission for Mathematical Instruction. The report is designed to inform rather than persuade.
\end{abstract}

\section{INTRODUCTION}

The paper opens with a brief historical sketch of the origins and evolution of the concept of 'numeracy', then looks at some definitions and proceeds to raise some issues concerning numeracy in general and the relationship between mathematics and numeracy in particular. The report ends with a brief look at Ireland's performance in some recent surveys that might be deemed relevant to this discussion.

\section{BRIEF SKETCH}

Surprisingly, the research literature contains no universally accepted definition of numeracy. Indeed in some non-English speaking countries there is no corresponding term in the language for what it is or signifies. For example, in some countries e.g. Austria, Germany, such debate as there is on related issues, is treated under Mathematics or Mathematics Education (FitzSimons et al, 1996). Interestingly, Ireland has no explicit official definition of numeracy despite its widespread currency in official reports and educational documents.

Cockcroft (1982) identifies the source of the concept and the term numeracy as the Crowther Report (1959) and in his report advances what he considers to be a well-rounded definition (Appendix). Crowther defined numeracy 'as the mirror image of literacy' (par. 398) and went on to elaborate his view (Appendix). Literacy and numeracy were seen as personal attributes that were needed to 
support the life-long aspirations of an educated person and that included communication between the so-called 'two cultures'. They were seen as overlapping complementary attributes. This view is elaborated in the following quote from the report:

By 'numeracy' we mean not only the ability to reason quantitatively but also some understanding of scientific method and some acquaintance with the achievement of science (par. 419 (a)).

Consequently, literacy and numeracy have remained bracketed together in the public consciousness, and numeracy issues and provision are subsumed under literacy. And so it remains until today when literacy still influences all major discussions on numeracy. The concept of numeracy follows what may be described as an evolutionary trail that can be described roughly as follows:

(1) mirror image of literacy

(2) literacy (no explicit concern for numeracy)

(3) literacy (concern for 3R's and basic mathematical skills)

(4) functional numeracy (detached from literacy)

(5) literacy (numeracy is recognised as an aspect e.g. quantitative literacy)

(6) types of literacy (e.g. mathematical literacy, scientific literacy, etc)

(7) numeracy (independent life skill detached from literacy/ equally important).

It is interesting to note that virtually all the definitions of literacy found in United Nations documents over 50 years include calculating or mathematics (Gal, 2000).

\section{NUMERACY - WhAT DOES IT MEAN?}

In practice the term may signify any one of a number of things including, basic computational arithmetic, essential mathematics, social mathematics, survival skills for everyday life, quantitative literacy, mathematical literacy and an aspect of mathematical power. These descriptions span a spectrum of personal abilities from basic skills to high-level cognitive abilities such as problem solving and communication.

For those who are more comfortable with definitions, several are available in the literature. These range across a mathematical spectrum from little or no mathematics to quite powerful mathematics. 
A small number of these have been selected for inclusion in the Appendix. The Cockcroft definition is the most famous.

\section{ISSUES CONCERNING NUMERACY}

Clearly there is an issue of meaning. When we talk about numeracy what do we mean precisely? To some extent this has been dealt with above but the matter does not end there. There is a wider debate that is only signalled here.

Other issues abound and only a brief selection is offered here. The implied issue in the title, namely the relationship between numeracy and mathematics, is addressed in a way that is clearly skewed in the direction of readers who are professional mathematicians and/or mathematics educators.

\section{a. Numeracy and school mathematics}

Numeracy impacts on individuals across their life span from child to adult and has implications for their education and lifelong learning in schools, in the work place and in other non-traditional settings. The relationship between numeracy and school mathematics is problematic not least because numeracy does not seem to be an automatic outcome for many after years of compulsory schooling.

Numeracy and literacy are prioritised in the Irish Primary School curriculum. While numeracy is not explicitly defined it is clear that there is a concern for basic mathematics as opposed to mere computational skills only (NCCA, 1999). For many practitioners and researchers in the field, it seems numeracy should not be equated with less mathematics but more in terms of sense making, application and decision making.

The juxtaposition of higher order abilities and basic mathematics captures an important insight that invites us to consider the combination comprising more advanced mathematics and higher order cognitive abilities. This connects neatly with the secondary school mathematics curriculum where the term numeracy is not generally used except in the context of under-achievement and early schoolleavers. Indeed, the goal of secondary school mathematics in the U.S. is mathematical literacy which is interpreted as a good secondary mathematics education that is necessary for all who aspire to higher education and work in an Information Age. 


\section{b. Numeracy and Higher Education}

The concept of numeracy has some currency in higher education specifically in the context of the so-called 'numerate disciplines'. Traditionally, there has been concern for the mathematics education of engineers, scientists and technologists. For example, Le Roux (1979) in the spirit of Crowther interprets numeracy in a higher education context as developing the mathematical ability of non-mathematicians to interact effectively with mathematicians and communicate their needs. More recently this debate has widened to encompass issues such as service mathematics teaching, mathematical under-preparedness and entry standards and more socially determined issues such as access, equality, disadvantage and the role of mathematics therein.

\section{c. Goals}

A wide range of goals for numeracy can be identified in national and international reports and literature. In general it is fair to say that numeracy is perceived as 'contributing to the empowerment, effective functioning, economic status, and well being of citizens and their communities' (Gal, 2000:ix). Steen (1997: xxii) refers to a useful summary of these goals associated with five different dimensions of numeracy as follows:

practical, for the immediate use in the routine tasks of life; civic, to understand major public policy issues; professional, to provide skills necessary for employment; recreational, to appreciate games, sports, lotteries; and cultural, as part of the tapestry of civilization.

All of these implicate education at some level but other agencies are also implicated e.g. training agencies, trade unions. However, it is not simply a matter of educational goals been driven by educational concerns but rather is it the case of strong economic and social policy pressures on education being marshalled to deliver aspects of government policy especially in the economic arena.

\section{Are there national indicAtors OF NUMERACy FOR IRELAND?}

There is no doubt that the first refuge of mathematicians confronted with this question is school mathematics. In Ireland in the 1950s it was associated with primary school mathematics and the 3R's. It 
has since advanced to include more mathematics and is probably related to grasp of Junior-cycle mathematics and for many this points specifically to Foundation Mathematics, and similarly for Foundation Mathematics at Leaving Certificate level. The indirect indicators are, and have been, the mathematics results on the State Examinations.

In recent years there have been international studies in mathematics and science and literacy and these have been used as indicators although it is not always clear what these measure or indicate. Ireland has participated in a number of such studies and four of these are listed below:

Second International Mathematics Study (SIMS)

Third International Mathematics and Science Study (TIMSS)

International Adult Literacy Study (IALS)

Programme for International Student Assessment (PISA).

A short summary of salient features of each study is included below:

\section{SIMS (1983-86)}

Main focus: Student achievement in mathematics.

Target group: Two populations, Population A (13 year-olds) and Population B (Final Year students).

Rank: Ireland withdrew from international version of tests but learned a lot about national curriculum from this involvement.

Definitions: The mathematics content was assessed by tests in arithmetic, algebra, geometry, measurement, descriptive statistics (Population A); and sets, relations, functions; number systems, algebra, geometry, analysis, probability and statistics (Population B). Acknowledgement: I am grateful to my colleague Elizabeth Oldham for this information.

TIMSS (1995)

Main focus: Student achievement in mathematics and science.

Target group: Three populations, Irish results for Population 1 (9 year-olds) and Population 2 (13 year-olds) are given.

Rank: Population 1: 550 mean, ranked $5^{\text {th }}$

625 highest mean (Singapore)

Population 2: 527 mean, ranked $12^{\text {th }}$

643 highest mean (Singapore) 
Definitions: The mathematics content areas assessed were numbers, measurement, geometry, proportionality, functions, relations and equations, data analysis, probability and statistics, analysis.

IALS (1995)

Main focus: literacy

Target group: adults aged 16-64

Rank: $25 \%$ of Irish population scored at lowest level (level 1).

No other country had higher percentage at this level, except one. Definitions: This survey used three literacy scales; prose literacy, document literacy and quantitative literacy and these scales were used to identify five levels of literacy. Quantitative literacy was defined as the knowledge and skills needed to apply arithmetic to numbers incorporated in printed materials.

PISA (2000)

Main focus: reading literacy

Minor focus: mathematical literacy

Target group: 15-year-olds (end of compulsory education)

Rank: $5^{\text {th }}$ from 27 countries (reading literacy)

$15^{\text {th }}$ from 27 countries (mathematical literacy)

Special features: a. Focus on knowledge and skills needed for adult life

b. Mathematics test items not intended to reflect school mathematics.

Definitions: Mathematical literacy is defined as 'an individual's capacity to identify and understand the role mathematics plays in the world, to make well-founded mathematical judgements and to engage in mathematics, in ways that meet the needs of that individual's current and future life as a constructive, concerned and reflective citizen'.(PISA documentation)

The studies listed above explain clearly the measures used and the way the data is interpreted. For this paper it is necessary to distinguish between literacy, quantitative literacy, mathematical literacy and numeracy. Certainly from a mathematics perspective quantitative literacy focusing as it does on very basic mathematical skills for all citizens is less demanding than mathematical literacy which mathematicians are likely to associate with the outcomes of school mathematics. Where does that take us in terms of this report? We could say that we have several national indicators of numeracy or 
none but in this regard it is comforting to note that we are probably no better or worse than other developed countries.

\section{Conclusions}

Numeracy, in its many guises, is likely to be a significant issue for government policy makers into the future. This is flagged in policy documents related to economic growth and is implied in education policy as it relates to retention at second level and third levels and the drive to mass higher education. Clearly, related policy decisions will impact on educational policy at all levels including mathematics and science education. Among the many stakeholders in numeracy, quantitative or mathematical literacy or whatever new term may be coined, are mathematicians and mathematics educators. Important stakeholders should be actively involved at all levels.

\section{Appendix}

\section{Selected definitions of numeracy}

\section{Crowther (1959: par 401):}

'On the one hand is an understanding of the scientific approach to the study of phenomena - observation, hypothesis, experiment, verification. On the other hand is a need in the modern world to think quantitatively, to realise how far our problems are problems of degree even when they appear as problems of kind.'

\section{Cockcroft (1982: par 39):}

'We would wish 'numerate' to imply the possession of two attributes. The first of these is an 'at-homeness' with numbers and an ability to make use of mathematical skills which enable an individual to cope with the practical mathematical demands of his everyday life. The second is ability to have some appreciation and understanding of information which is presented in mathematical terms, for instance in graphs, charts or tables or by reference to percentage increase or decrease.'

\section{Steen (1997: $\mathrm{xx})$ :}

'There appears to be reasonable consensus among individuals of widely differing perspectives on the natural growth of numeracy from the basic arithmetic of grade school through the more sophisticated numerical reasoning of measurement, ratios, percentages, graphs, 
and exploratory data analysis that is now the centerpiece of middle school mathematics.'

Dossey (1997: 173):

'To understand the meaning of quantitative literacy, a better model is one based on a categorization of mathematical behaviors into six major aspects:

Data representation and interpretation-Number and operation sense - Measurement-Variables and relations-Geometric shapes and spatial visualization-Chance

These aspects provide a broad basis for examining the ability to interpret and act in a wide variety of mathematics-related settings.'

\section{Johnston (1994: 34):}

'To be numerate is more than being able to manipulate numbers, or even being able to 'succeed' in school or university mathematics. Numeracy is a critical awareness which builds bridges between mathematics and the real world, with all its diversity.'

... 'in this sense...there is no particular 'level' of Mathematics associated with it: it is as important for an engineer to be numerate as it is for a primary school child, a parent, a car driver or gardener. The different contexts will require different Mathematics to be activated and engaged in...'

\section{Australian Council of Adult Literacy (1991):}

Literacy involves the integration of listening, speaking, reading, writing and critical thinking; it incorporates numeracy. It includes the cultural knowledge which enables a speaker, writer or reader to recognise and use language appropriate to different social situations. For an advanced technological society such as Australia, the goal is an active literacy which allows people to use language to enhance their capacity to think, create and question, in order to participate effectively in society.

From: Policies and Pedagogies for Lifelong Literacy: International Perspectives for the $21^{\text {st }}$ Century, 2001, p. 5 .

\section{REFERENCES}

Central Advisory Council for Education (England) (1959) A report of the Central Advisory Council for Education (England), Crowther Report. London: HMSO

Cockcroft Committee (1982) Mathematics Counts: A Report into the Teaching of Mathematics in Schools. London: HMSO. 
Dossey, J. A. (1997). Defining and measuring quantitative literacy. In L.A Steen (ed.) (1997) Why numbers count: quantitative literacy for tomorrow's America. New York: College Entrance Examination Board, 173-186.

FitzSimons, G. E., Jungwirth, H., Maasz, J., Schloeglmann, W. (2000) Adults and Mathematics (Adult Numeracy). In G. E. FitzSimons, , D. Coben,., and J O'Donoghue (eds.) (2000) Perspectives on Adults Learning Mathematics: Research and Practice. Dordrecht: Kluwer Academic, 755-784.

Gal, Iddo (ed.) (2000) Adult Numeracy Development: theory, Research, Practice. New Jersey: Hampton Press.

Johnston, B (1994) Critical Numeracy. Fine Print, 16(4). 32-36.

LeRoux, A.A. (1979), International Journal of Mathematical Education in Science and Technology, 10, 343-354.

Morgan, M., Hickey, B. and Kellaghan, T. (1997) International Adult Literacy Survey Results for Ireland. Dublin: Stationery Office

NCCA (1999) Primary School Curriculum: Introduction. Dublin: Stationery Office.

Shiel G., Cosgrove, J., Sofroniou, N., Kelly, A. (2001) Ready for Life? The literacy achievements of Irish 15-year olds with comparative international datasummary report. Dublin: Educational Research Centre.

\title{
OTHER USEFUL REFERENCES
}

FitzSimons, G. E., Coben, D., and J O'Donoghue (eds.) (2000) Perspectives on Adults Learning Mathematics: Research and Practice. Dordrecht: Kluwer Academic.

FitzSimons, G. E., O'Donoghue, J. and D. Coben (2001). Adults and Lifelong Education in Mathematics. Melbourne: ALM and Language Australia.

Kaiser, G., Luna, E. and I. Huntley (eds.) (1999). International comparisons in Mathematics Education. London: Falmer Press.

\section{WEBSITES}

\author{
http://www.erc.ie/pisa \\ http://www.SourceOECD.org \\ http://www.alm-online.org \\ http://www.irlgov.ie/educ/ \\ http://nces.ed.gov/timss/
}

John O'Donoghue,

Department of Mathematics and Statistics,

University of Limerick,

Limerick, Ireland

John.ODonoghue@ul.ie 